\title{
El tratamiento de la información infográfica de La Vuelta Ciclista a España 2017 en elmundo.es
}

\author{
Dra. Begoña Ivars Nicolás | bivars@umh.es \\ Universidad Miguel Hernández
}

Palabras clave

infografía periodística; El Mundo; acceso a la

información; interactividad; hipertextualidad;

recuperación de la información

Sumario

1. Introducción. 2. Metodología. 3. Resultados. 4.

Discusión. 5. Conclusiones. 6. Bibliografía.

7.Agradecimientos

\section{Resumen}

La infografía ha evolucionado notablemente en el medio internet convirtiéndose en una unidad informativa autónoma integrando cualidades como la hipertextualidad o la interactividad. Además, adquiere relevancia en secciones como Deportes o Economía. Sin embargo, en España la infografía sigue siendo principalmente un complemento del texto de la noticia, raramente aprovecha las cualidades del medio, y tampoco logra hacerse un hueco como la fotografía o el vídeo en la organización de la información de

los cibermedios. Este texto presenta los resultados de un estudio de caso sobre el tratamiento de la infografía en las noticias sobre la Vuelta Ciclista a España 2017 en el diario elmundo.es. Se atiende a dos aspectos: el acceso y la recuperación de la información infográfica; y la aplicación de la hipertextualidad y la interactividad en las infografías halladas. Destaca la dificultad para encontrar infografías mediante las herramientas proporcionadas para la recuperación de la información. Además, sobresale el estatismo de éstas y el aprovechamiento mínimo la interactividad.

\section{Cómo citar este texto:}

Begoña Ivars Nicolás (2017): "El tratamiento de la información infográfica de La Vuelta Ciclista a España 2017 en elmundo.es”, en Miguel Hernández Communication Journal, n8, pp. 671 a 698. Universidad Miguel Hernández, UMH (Elche-Alicante). Recuperado el__ de de 20 _ de: link del artículo en mhjournal.org] 


\title{
The treatment of infographic information of the Vuelta Ciclista to Spain 2017 in elmundo.es
}

\author{
Dra. Begoña Ivars Nicolás | bivars@umh.es \\ Universidad Miguel Hernández
}

\section{Keywords}

journalistic infographics; El Mundo; access to information; interactivity; hypertextuality;

information retrieval

Summary

1. Introduction. 2. Methodology. 3. Results. 4.

Discussion. 5. Conclusions. 6. Bibliography.

7.Acknowledgments

\begin{abstract}
Infographic has evolved in the internet medium becoming an autonomous information unit integrating qualities such as hypertextuality or interactivity. In addition, it acquires relevance in sections such as Sports or Economy. In Spain, however, infographics continue to be mainly a complement to the text of the news, rarely exploiting the qualities of the medium, nor does it manage to create a niche such as photography or video in the organization of the cybermedia. This text presents the results of a case study on the
\end{abstract} treatment of infographics in the news about the Tour of Spain 2017 in the newspaper elmundo.es. It addresses two aspects: access and retrieval of infographic information; and the application of hypertextuality and interactivity in the infographics found. It highlights the difficulty to find infographics using the tools provided for the retrieval of information. In addition, the statism of these stands out and the minimal use of interactivity.

How to cite this text:

Begoña Ivars Nicolás (2017): "The treatment of infographic information of the Vuelta Ciclista to Spain 2017 in elmundo.es”, en Miguel Hernández Communication Journal, nº, pp. 671 to 698, Universidad Miguel Hernández, UMH (Elche-Alicante). Accessed 20_ in: [paper link in mhjournal.org] 


\section{Introducción}

La infografía ha experimentado una notable evolución en el medio internet al poder integrar hipertextualidad, interactividad o multimedialidad en una unidad informativa autónoma. Además, en los medios de comunicación en la red, adquieren relevancia contenidos de información gráfica, especialmente en la sección de deportes, para mostrar datos, técnicas deportivas, jugadas destacadas, etc. Sin embargo, tras una revisión general al panorama mediático español, parece que la infografía no llega a despegar como unidad autónoma de información, apenas se aprovechan las cualidades del medio para potenciar la inmersión del lector, ni logra un hueco como la fotografía o el vídeo en la organización de la información de los cibermedios.

Este texto presenta los resultados de un estudio de caso sobre el tratamiento de la infografía en la Vuelta Ciclista a España de 2017 en el diario español de prensa generalista elmundo.es. Se atiende a dos aspectos fundamentalmente: el acceso y la recuperación de la información infográfica; y el aprovechamiento de la hipertextualidad y la interactividad en las infografías halladas.

\subsection{El cibermedio y el webperiodismo.}

Internet ofrece unas características que permiten avances periodísticos en cuanto a formas de contar la información, medios para distribuirla, almacenarla y recuperarla, la frecuencia de actualización de los contenidos, la generación de los mismos centrados en minorías para llegar a más públicos, etc. Estos factores suponen un atractivo irresistible para los editores, habiéndose asentado el "cibermedio" como una categoría más del periodismo a la altura de los medios impreso, radiofónico y televisivo (López García, X. et al., 2005: 40). Xosé López y otros autores entienden el cibermedio como: "Aquel emisor de contenidos que tiene la voluntad de mediación entre hechos y público, utiliza fundamentalmente criterios y técnicas periodísticas, usa el lenguaje multimedia, es interactivo e hipertextual, se actualiza y se publica en la red Internet" (López García, X. et al., 2005: 40). Es decir, se trata del soporte para el periodismo en Internet, como la televisión lo es para el periodismo televisivo.

El concepto de periodismo debe estar directamente relacionado con el soporte técnico y el medio que difunde las noticias (Murad, A. 1999), por lo que la palabra webperiodismo (Canavilhas, J. 2001; Mielniczuk, L. 2003; Ribas, B. 2004; Alzamora, G. 2004; Barbosa, S. 2005) es la que mejor se adecua al periodismo hecho en y para Internet, específicamente en la parte de Internet denominada World Wide Web. Por lo tanto, lo que entendemos por webperiodismo es el periodismo que utiliza las herramientas de Internet para 
investigar y producir contenidos periodísticos y difundidos por la Web. Además presenta un lenguaje propio compuesto por textos, sonidos, imágenes y animaciones conectados entre sí a través de enlaces.

Ramón Salaverría y Díaz Noci (Salaverría, R. et al., 2005b) proponen tres características principales que definen el ciberperiodismo: la hipertextualidad, la multimedialidad y la interactividad. Bardoel y Deuze (2001) han incluido en este grupo la personalización de contenidos; Palacios añade dos más: la memoria y la actualización continua (Palacios, M. 2003 en Canavilhas, J. 2007b: 52). Son estas seis características las que nos permiten definir los códigos periodísticos del nuevo medio (Canavilhas, J. 2007b: 52). Existen diferentes clasificaciones $\mathrm{y} / \mathrm{o}$ definiciones, sin embargo parece haber un acuerdo en acentuar como principales características la hipertextualidad, la interactividad y la multimedialidad sobre las demás.

En esta investigación interesa especialmente conocer y contextualizar la hipertextualidad, la interactividad y la memoria del cibermedio para entender mejor los resultados del estudio. Además, cabe aclarar que la infografía se considera una noticia en el sentido de que es una pieza informativa. Narra, contextualiza o muestra información pero en vez de emplear el texto, la imagen gráfica adquiere el protagonismo por exigencias del tipo de información que se quiere comunicar. Por lo tanto, las referencias bibliográficas de este texto que hacen referencia a noticias o piezas informativas se consideran igualmente válidas para las infografías.

\subsection{La memoria, la interactividad y la hipertextualidad. 1.2.1. La Memoria}

La memoria se define como la capacidad que ofrece el cibermedio de recuperar la información que ha sido almacenada en bases de datos. Se trata de una memoria múltiple, instantánea y acumulativa, en la que la inserción de datos pueden realizarla tanto los productores como por los usuarios (Palacios, M., 2002, 2003: 13-36).

La memoria abarca aspectos relacionados con el acceso, la lectura, la presentación y recuperación de la información que se publica. Además, el modo y las herramientas que se le ofrecen al lector para acceder a los contenidos están ligados a la accesibilidad del sitio. En este sentido, MartínezRubio (2008: 99-140) expone que "son relevantes aspectos como la arquitectura de la web, la usabilidad y la evaluación de existencia de sistemas para la recuperación de la información digital": 
La arquitectura web se ocupa de la forma en la que va a ser presentada la información. Según Coutin, A., (2002: 21-27) los componentes con los que trabaja directamente la arquitectura de la información son cuatro: los sistemas de navegación, los sistemas de etiquetas, los sistemas de organización e indexado y los métodos de búsquedas y metáforas. En el ámbito de la distribución de la información los primeros problemas que afectan a este canal son: la accesibilidad, el desbordamiento cognitivo y la desorganización (Rodríguez Yunta, L. et al., 2004). En cuanto a la accesibilidad, destaca la gran cantidad de información disponible y su desigualdad a la hora de su acceso; el desbordamiento cognitivo, por la cantidad de información disponible que resulta difícil seleccionar y evaluar este tipo de información; y la desorganización, puesto que los recursos digitales suelen aparecen sin una estructura lógica que dificulta su recuperación a partir de unas necesidades concretas de búsqueda.

Los mecanismos de acceso que ofrecen los cibermedios españoles se agrupan en cuatro categorías según lo que quiere el usuario y su procedimiento. La siguiente propuesta parte de la realizada por Centelles (2005) pero, debido a la influencia de las plataformas sociales en la difusión de la información, se añaden los servicios para compartir información y se establece la evolución de los sistemas de acceso y recuperación de la información en los cibermedios en 3 fases (Ivars-Nicolás, B. 2012b: 397-399):

Navegación: el lector quiere tener acceso a información y navega para localizarla mediante menús, índices, listas, titulares o mapa del sitio; Búsqueda: el lector quiere recuperar información y utiliza buscadores, hemerotecas o archivos; Suscripción/activación: el lector quiere recibir información y se suscribe en sistemas como alertas, envío de titulares y boletines, sindicación y descarga de widgets; Y difusión: el lector quiere compartir información y la difunde en otras plataformas o dispositivos con opciones para compartir, en su red social, importa códigos, etc. [...] 1) Inicialmente se navegaba por el cibermedio para localizar la información mediante menús. Esta navegación se implementó con estructuras como índices, titulares o mapas contextuales para facilitar y agilizar el acceso a los contenidos; 2) Posteriormente, la información se ha organizado en bases de datos conformando la memoria del sitio (Canavilhas, J. 2007; Abadal, E. y Guallar, J. 2010). Estos sistemas de almacenamiento permiten recuperar contenidos usando sistemas de consulta como motores de búsqueda y hemerotecas; 3) A estos servicios de valor añadido se suman otros alternativos de acceso a la información.

Para establecer la capacidad de memoria de un sitio se puede buscar la existencia de estas herramientas y verificar su correcto funcionamiento. 
Además, a partir de una experiencia de usuario, se puede establecer si son instrumentos ágiles, usables y eficaces. Es posible que un cibermedio tenga buscador pero no disponga de filtros acertados que ayuden a concretar la búsqueda y el resultado sea tal cantidad de información que produzca un desbordamiento cognitivo que invite al lector a abandonar la página. En definitiva, se trata de ofrecer modos de lectura, consulta y recuperación que tengan en cuenta las necesidades del lector.

\subsubsection{La Hipertextualidad}

La hipertextualidad es la capacidad de interconectar diversos textos digitales entre sí, conformando un hipertexto, y la cualidad hipertextual que presentan determinados documentos (Salaverría, R., 2005a: 29). Para Salaverría (2005a: 28), el hipertexto es "Un documento poliformo que se construye enlazando distintas piezas textuales y/o audiovisuales, interconectadas entre sí gracias a la tecnología digital". Lluís Codina prefiere utilizar la palabra hiperdocumento porque no sólo se conforma de contenidos textuales sino que se trata de "un documento digital complejo, formado por un conjunto de elementos no necesariamente homogéneo, dotado de una determinada composición interna y que se puede leer o visualizar de una manera no necesariamente secuencial" (Codina, L., 2003: 144). En este pensamiento, Codina se aproxima más al uso de la hipertextualidad conformada por texto, imágenes, sonidos, vídeos, etc., introduciendo también nuevos términos como la multimedia y el hipermedia.

Ambos autores coinciden en que la construcción del hipertexto o hiperdocumento se dirige a un orden de lectura en el que el lector va determinando conforme lee, es decir, una lectura tridimensional que puede variar en cualquier momento y que es totalmente controlada por el usuario. En este sentido, los elementos que forman parte del hiperdocumento adquieren más profundidad, pues ya no sólo poseen una función informativa, sino que alcanzan nuevos propósitos.

El hipertexto evoluciona estableciendo una serie de estructuras (Toschi, L. 2001; Powell, T.A. 2001; López García, X. et al., 2002; Codina, L. 2002; Díaz Noci, J. y Salaverría, R. 2003; Rovira, C. 2002a y 2002b; Carvalho, M. 2005) para aplicar a las informaciones periodísticas que dan lugar a narrativas propias del cibermedio cuyos elementos principales son los nodos y los enlaces. El nodo es cada una de las unidades de información o elementos que conforman un hipertexto. Y el enlace, hipervínculo o link son unidades básicas que conectan y ayudan a organizar los contenidos en la red conformando o presentando las estructuras antes mencionadas (Díaz Noci, J. et al., 2003: 102103), es decir, la unión entre nodos y secciones (Codina, L. 2003). 
Partiendo de lo explicado, elaborar un hiperdocumento no consiste en transformar palabras o imágenes en enlaces, sino que la pieza se debe construir a base de estructuras discursivas compuestas por fragmentos textuales o multimedia. Para ello, es necesario establecer niveles de nodos, y también organizar los recorridos entre estos nodos para que el lector pueda moverse con coherencia.

Ramón Salaverría (2005a: 101-106) propone una tipología en base a las estructuras hipertextuales que se pueden utilizar en la narración de relatos o en la exposición de datos ciberperiodísticos. Estas estructuras pueden ser axiales lineales, reticulares o mixtas: La estructura axial organiza el discurso en torno a un eje central marcando el camino, es decir, presenta una línea discursiva clara aunque, según se organice, se propongan diferentes alternativas para seguirla. Se usa para la narración o argumentación. Existen diferentes estructuras axiales: La estructura axial unilineal se produce cuando sólo hay un eje central y la lectura es consecutiva, aunque en diferentes nodos.

\section{Figura 1. Esquema de la estructura axial unilineal.}

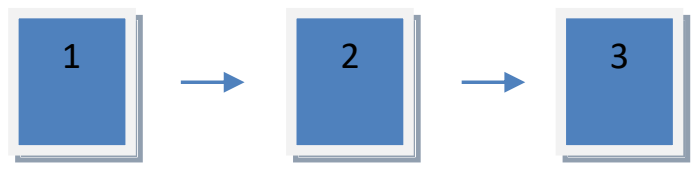

Fuente: adaptado de Salaverría, R., 2005a: 101-106.

La estructura axial multilineal que se produce cuando en ese eje central se presentan varias alternativas en un mismo nivel ampliando las posibilidades del recorrido de lectura. Pueden ser arbóreas (figura izquierda) o paralelas (figura derecha). 
Figura 2. Esquema de la E. axial multilineal arbórea y multilineal paralela. 2005.
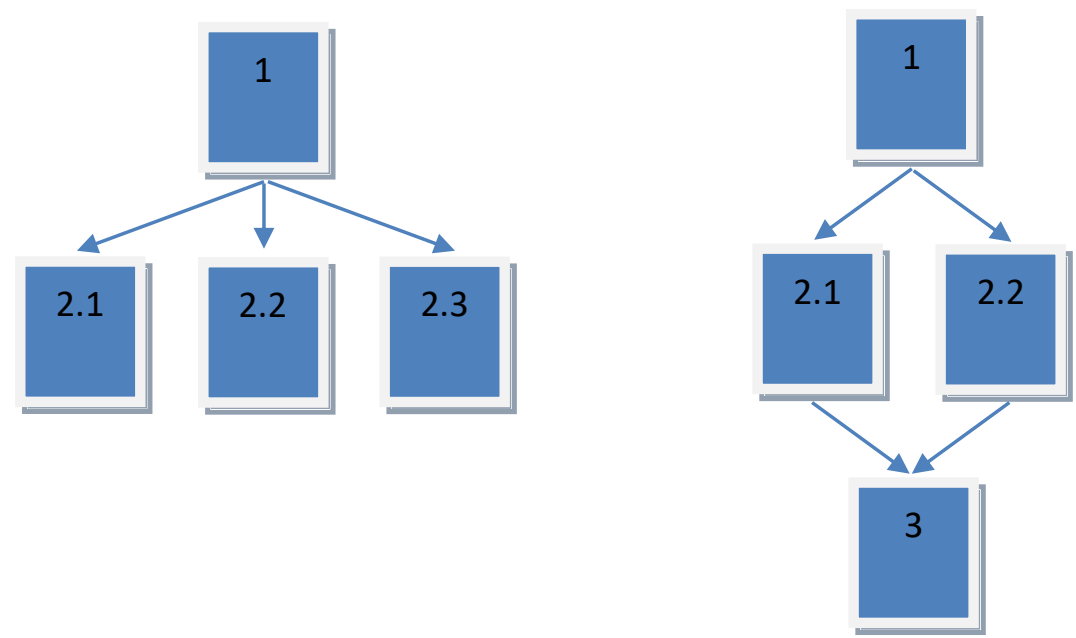

Fuente: adaptado de Salaverría, R., 2005a: 101-106.

Por otro lado, la estructura reticular está marcada por la ausencia de un eje central discursivo, posibilitando diversos itinerarios de lectura y navegación entre los nodos. Se usa para estructuras no lineales, sin eje narrativo, como contenidos expositivos y, a veces, argumentativos. Las estructuras se pueden integrar o yuxtaponer.

Figura 3. Esquema de la E. reticular o no lineal. 2005.

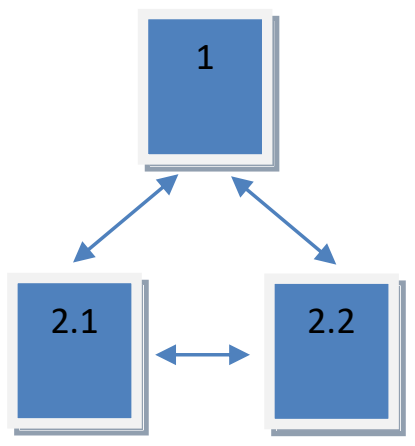

Fuente: adaptado de Salaverría, 2005a: 101-106. 
Una práctica que se comienza a encontrar en algunos cibermedios se basa en estructuras (centrándonos en las piezas informativas) que son unilineales en sus primeros nodos pero multilineales arbóreas en el tercero, o reticulares, etc. Dee-Lucas ha realizado diferentes tipos de distribución del texto concluyendo que la estructura arbórea es la más rápida y fácil en comparación con la distribución en listas, cuyo acceso suele ser más lento y difícil, y con la organización en texto lineal tradicional que pretende transmitir calidad, pero es la más lenta de las tres propuestas (Dee-Lucas, D., 1996 en Marcuschi, L. A., 1999). Para Díaz Noci y Salaverria (2003) la estructura hipertextual mixta que combina las ya expuestas es la mejor opción para la pieza informativa abriendo nuevos caminos de lectura.

La estructura axial lineal se puede considerar estática para un cibermedio. Manuel Gago plantea que los sitios estáticos reproducen "directamente las condiciones de lectura de un periódico en formato papel” utilizando una linealidad básica, aunque introduzca leves intentos de hipertextualidad interna y externa como pueden ser los menús de navegación o los índices o sumarios (Gago, M., 2006: 97). Por el contrario, un cibermedio dinámico es el que se apoya en bases de datos y en los sistemas de recuperación de información. Debido al aumento del volumen de la información que dicho espacio maneja y en el tipo de contenidos: sonidos, textos, infografías, imágenes, etc., éstos se organizan en bases de datos interactivas. Esta ordenación da lugar a múltiples relaciones entre elementos y por tanto a resultados de visualización de la información muy diferentes y diversos, según lo que el usuario solicita. (Díaz Noci, J., 2008: 81).

En este punto cabe mencionar que la hipertextualidad permite innovar dando lugar a una arquitectura de la información diferente a la utilizada en prensa que se ajuste a las necesidades del lector y las posibilidades del medio. "Al integrar hipermedia en la noticia y, sobre todo, señalar las rutas de lectura, el hipertexto abre un rol de opciones cuya organización obliga al periodista a seguir principios de construcción que ayuden al lector” (Hall, 2001).

Como explica el profesor Canavilhas (2007b: 61), si el Webperiodismo se basa en una estructura multienlace, se trata de una noticia construida en varios nodos o bloques de información interconectados por varios enlaces. La arquitectura de la información, en este caso, se organizará para que el lector no se pierda, tenga garantizada la información esencial sobre lo relatado en la noticia y, además, obtenga la información complementaria que demanda pero en niveles de profundidad. Canavilhas (2007b: 86) propone una estructura basada en la pirámide tumbada "en la que la noticia se desarrolla de forma horizontal de menos información a más información sobre cada uno de los 
elementos de la noticia (qué, quién, dónde, cuándo, cómo, por qué)" permitiendo la personalización del lector que "es quien decide qué leer y cómo leer la información". En el caso del webperiodismo y la pirámide tumbada "la variable ya no es la importancia de la información para el periodista (másmenos: base arriba y vértice abajo) si no la cantidad de información ofrecida (menos-más: vértice a izquierda y base a derecha)" (Canavilhas, J. en Ivars Nicolás, B. 2010: 50-65). Así, el lector profundiza en lo que realmente le interesa.

\subsubsection{La Interactividad}

La interactividad es otra cualidad destacada del medio Internet. A comienzos del siglo XXI, Sádaba definió la interactividad como la capacidad tecnológica que consigue equiparar el proceso de comunicación que se produce mediante la tecnología, al diálogo (Sádaba, M. R., 2000: 139-166). Sádaba distinguía entre la comunicación entre un usuario y un ordenador, y la comunicación entre personas, siempre intervenida por la tecnología. Pereira (2006: 175), por ejemplo, trata también la diferencia entre la interactividad entre personas, y la interactividad entre personas y máquinas. La mayoría de investigadores establece dos tipos de interactividad, y aunque les nombren de diferente manera, obedecen al objeto o al sujeto con el que el usuario inicia el diálogo.

Apoyada en la misma línea sigue la tesis de Rost, que entiende la interactividad como la capacidad que tiene un medio de comunicación para dejar participar al lector en la selección de los contenidos y en las posibilidades de expresión y comunicación. Este autor establece tres tipos de interactividad: La selectiva en la que se interactúa con los contenidos; La comunicativa generando interacción entre los individuos; Y una combinación de ambas produciéndose la interacción con los contenidos y entre individuos (Rost, A., 2006: 285-300 y 353- 358). Va creciendo la complejidad de la interactividad desde una relación de diálogo a través del ordenador, entre lector y periodista, hasta cuando el lector se descarga un vídeo, vota una noticia o participa en una encuesta.

Una perspectiva diferente pero no contraria la aporta Ryan (2004: 22) quien relaciona ambos conceptos, interactividad e hipertexto, y distingue entre la implicación del lector en la producción del significado atendiendo a la exploración y al recorrido que éste realice por el hiperdocumento, interactividad selectiva, y, por otro lado, la implicación del lector en la producción del hiperdocumento, en su elaboración, (interactividad productiva). Se puede considerar interactividad la acción de navegar por un texto o por el sitio Web, en cuanto a que el lector elige su camino, no participa 
en los contenidos, sólo en cómo se estructuran para leerlos. "O sea, el lector no domina el qué pero al menos domina el cómo” (Salaverría, R., 2005b:34).

Conforme vamos ahondando en el significado de interactividad se van añadiendo agentes relacionados y se va formando un concepto más preciso. No sólo hay que tener en cuenta entre quiénes se establece la relación, si no qué libertad hay dentro de la misma. Ahí es donde entra la inmersividad en cuanto a la sensación del usuario de sentirse sumergido en una realidad diferente a la que se encuentra físicamente. En el cibermedio se trata, por ejemplo, de la navegación que permite al lector moverse por determinados espacios y elementos interactuando. En definitiva, cualquier posibilidad que ofrezca una experiencia de uso particular que fomente la implicación del usuario y por tanto su sentido de participación. Y esto es habitualmente mediante enlaces de navegación y herramientas de servicios de valor añadido que estimulan la comunicación, la personalización o la participación del usuario. Como ejemplos, cabe mencionar: el zoom; el navegador; el buscador; opciones de adaptar el contenido en tamaño, color, etc. según las necesidades; o sistemas de suscripción para elegir el tipo de información, cómo, dónde y cuándo se desea recibir; el email; sistemas de comentarios o de votación; etc.

Como explica Beatriz Marín Ochoa (2009: 279), se rompe la linealidad y el hipertexto introduce una tercera dimensión que facilita la interrelación de los mensajes en múltiples direcciones lo cual lleva a los usuarios a navegar en diversas esferas de la información.

\subsection{La infografía periodística.}

Para comprender mejor el asunto que se aborda, cabe explicar brevemente qué tipo de informaciones periodísticas se exponen mediante la infografía porque no todo hecho periodístico se puede o se recomienda plasmar mediante la infografía.

A comienzos de la última década del siglo XX, Peltzer (1991: 135) explicaba que mediante estas expresiones gráficas se narran hechos o acontecimientos, cómo funciona algo o cómo es una cosa. De Pablos apunta que se pueden representar datos numéricos mediante gráficos o contar una historia cuando no se dispone de imágenes fotográficas (1991: 159-160). Para De Pablos (1993: 273), la infografía se utiliza cuando falta algo por enseñar o no existe información fotográfica sobre el asunto y se quiere explicar o exponer las causas o el desarrollo del acontecimiento. Colle (1998: 1; 2004:1) destaca que "Lograr una buena información recurriendo principalmente al lenguaje visual [...] es el objetivo de la disciplina infográfica" en lugar de un discurso verbal 
complejo y largo. En esta apreciación coincide Jaime Serra quien matiza que "Hay que contar con el texto sólo lo que el dibujo no muestra, para evitar la redundancia" (Serra, J. 1998, en Borras, Leticia at adl. 2000). Y para IvarsNicolás (2016: 148-149) la infografía "[...] en ocasiones es el único modo de contar una historia o un proceso, etc. para la comprensión del lector [...]”. La infografía, tradicionalmente, se ha utilizado para relacionar datos, contextualizar o mostrar algo que es difícil de comprender con palabras como un proceso, un suceso, cómo es algo por dentro o su funcionamiento.

Con el asentamiento de Internet como medio de comunicación, cada uno de estos ejemplos puede adquirir mayor inmersividad y profundidad de información aportando calidad y diversidad si, al presentarla, se integran cualidades del medio Internet como la hipertextualidad, la interactividad o la multimedialidad, entre otras. La posibilidad de navegar por la pieza informativa facilita que la narración sea profunda permitiendo contextualizar, ahondar y complementar la información como se expone en el punto 1.2.2. Sin embargo, como veremos en las conclusiones, los cibermedios españoles no alcanzan este nivel con respecto a la infografía. Internet y las TICS están afectando directamente en el proceso para adquirir competencias profesionales en la práctica de la profesión periodística (Ivars-Nicolás, 2012a: 25), pero tanto la enseñanza del periodismo como las redacciones van a velocidad más lenta que las exigencias y necesidades del lector.

\section{Metodología}

Esta investigación se apoya en el estudio de casos (Neiman y Quaranta, 2006), escogiendo el tipo de caso único con una única unidad de análisis (Yin 1994). Se analiza el acceso a la información en general y el tratamiento de la información gráfica mediante la infografía de la Vuelta Ciclista a España 2017 en elmundo.es. Para ello, se ha seleccionado como muestra de estudio el conjunto de infografías publicadas en el diario generalista de pago elmundo.es que hacen referencia directa a la Vuelta Ciclista a España 2017. El estudio se ha realizado el 12 de septiembre de 2017.

La infografía, debido al tiempo de trabajo que implica, es escasa en la prensa generalista diaria. Sin embargo, la naturaleza del deporte y temática escogida vienen motivadas por el interés que conllevan en la audiencia, lo cual propicia la producción infografías. A la vez, al ser una acción planificada, permite al infógrafo trabajar con antelación en la elaboración de infografías sobre el funcionamiento del deporte, etc. También, permite preparar otras informaciones gráficas a falta de datos deportivos como la clasificación. Por 
ello, es una oportunidad que tiene el cibermedio para potenciar la hipertextualidad y la interactividad en las piezas.

Para seleccionar el cibermedio se han tenido en cuenta los datos obtenidos del resumen general del Estudio General de Medios contemplando la oleada entre abril de 2017 y marzo de 2017 y de la base de datos internacional Alexa. El medio de pago más leído en Internet es elpais.com, sin embargo, los resultados de búsqueda de la muestra de estudio han sido vagos.

Se ha utilizado el buscador interno con palabras clave (vuelta + ciclista + España + 2017). De los 10 primeros resultados obtenidos y ordenados por coincidencia, hacen referencia directa a información deportiva de la Vuelta los ubicados en las posiciones $3^{\mathrm{a}}, 4^{\mathrm{a}}$ y $5^{\mathrm{a}}$. Las $2^{\mathrm{a}}, 6^{\mathrm{a}}$ y $7^{\mathrm{a}}$ noticias no tienen que ver si quiera con deportes. El resto son noticias paralelas a la vuelta sobre patrocinadores o ciclistas. A partir de la $10^{\mathrm{a}}$ posición, la información corresponde al 2016. Si se ordenan los resultados por fecha, los primeros puestos los ocupan el Giro, la Formula 1 y la ruta española de pateras. Mediante el buscador no se ha obtenido una muestra fiable. Otra búsqueda se ha hecho con la palabra clave infografía (infografía + vuelta + ciclista + España), pero los resultados en el primer caso son tanto noticias con infografías como con fotografías, o que se refieren a la palabra. En el segundo, aparecen noticias de la Vuelta pero sin infografías. Como último intento se ha navegado usando los menús pero tampoco se ha encontrado una sección de multimedia o de infografía.

Dados estos resultados, se ha decidido abandonar este medio. Se ha seguido el mismo procedimiento en el segundo cibermedio generalista más leído y, tras una primera búsqueda en elmundo.es y obtener resultados válidos, se ha determinado como cibermedio objeto de estudio.

Como siguiente paso, se ha intentado localizar la muestra objeto de estudio utilizando las distintas herramientas de acceso a la información dentro del cibermedio, propuestas en el marco teórico. y se han valorado procesos y resultados de forma cualitativa. Se han excluido de este estudio aquellos instrumentos o servicios destinados a recibir la información fuera del cibermedio. 
Tabla 1. Ficha: Análisis de la memoria del cibermedio. 2017.

\begin{tabular}{|c|c|}
\hline \multicolumn{2}{|l|}{ Ficha Memoria } \\
\hline \multicolumn{2}{|c|}{$\begin{array}{l}\text { Explica, paso por paso, cómo se puede recuperar una noticia en este } \\
\text { cibermedio: }\end{array}$} \\
\hline \multicolumn{2}{|l|}{ Navegación } \\
\hline \multicolumn{2}{|l|}{ Mapa Web } \\
\hline \multirow[t]{5}{*}{ Menú } & Menú principal. \\
\hline & Submenús. \\
\hline & Submenú por secciones. \\
\hline & Submenú desde el menú principal. \\
\hline & Otros. Especificar: \\
\hline \multicolumn{2}{|l|}{ Índice } \\
\hline \multicolumn{2}{|l|}{ Búsqueda } \\
\hline \multicolumn{2}{|c|}{ Buscador externo (Google, etc.) } \\
\hline \multirow[t]{6}{*}{ Buscador interno } & Buscador general. \\
\hline & Buscador por secciones. \\
\hline & Todas las secciones. \\
\hline & Alguna sección. Especificar: \\
\hline & $\begin{array}{l}\text { Buscador por tipo de contenido (texto, imagen, } \\
\text { vídeo, etc.). }\end{array}$ \\
\hline & Otros. Especificar: \\
\hline \multicolumn{2}{|l|}{ Hemeroteca externa } \\
\hline \multirow[t]{6}{*}{ Hemeroteca interna } & Hemeroteca general. \\
\hline & Hemeroteca por secciones. \\
\hline & Todas las secciones. \\
\hline & Alguna sección. Especificar: \\
\hline & $\begin{array}{l}\text { Hemeroteca por tipo de contenido (texto, } \\
\text { imagen, vídeo, etc.). }\end{array}$ \\
\hline & Otros. Especificar: \\
\hline
\end{tabular}

Fuente: Elaboración propia.

A continuación, se ha analizado cualitativa y cuantitativamente la hipertextualidad y la interactividad de cada una de las infografías obtenidas atendiendo a las siguientes fichas de análisis: 
Tabla 2. Ficha: Análisis de la hipertextualidad del cibermedio. 2017.

\begin{tabular}{|l|l|}
\hline Ficha Hipertextualidad \\
\hline Esquema completo de la estructura de la infografía. Deben tenerse en cuenta \\
sólo los nodos que contienen información noticiosa sobre el asunto, \\
omitiendo otros nodos no relevantes. Determinar en cuántos nodos se \\
lee/consume la infografía y cómo está organizada:
\end{tabular}

Fuente: Elaboración propia.

Tabla 3. Ficha: Análisis de la interactividad del cibermedio. 2017.

\begin{tabular}{|l|l|}
\hline \multicolumn{2}{|l|}{ Ficha Interactividad } \\
\hline Ofrece elementos interactivos (Sí/No): \\
\hline \multicolumn{2}{|l|}{ Tipo de elemento interactivo (repetir para cada elemento): } \\
\hline & Descripción: \\
\hline & Tipo de interactividad (selectiva, comunicativa o ambas): \\
\hline & $\begin{array}{l}\text { Valora el nivel de manipulación de la información, si se permite, y explica } \\
\text { en qué consiste (interactividad selectiva o productiva): }\end{array}$ \\
\hline
\end{tabular}

Fuente: Elaboración propia.

\section{Resultados}

El cibermedio elmundo.es dispone de buscador interno, menú principal y submenús perfectamente visibles en la página de inicio. También tiene hemeroteca interna en la que el lector puede, previo pago, suscribirse a la edición diaria y descargarla, y/o a la hemeroteca completa. La hemeroteca, al ser de pago, no se ha estudiado. 
El buscador funciona con palabras clave y permite filtrar simultáneamente por noticias, blogs, fotos, vídeos y América. Además, por fecha, sección y suplemento. Se ha observado que, conforme se afina por filtros, estos a la vez proporcionan un segundo nivel de filtrado. Por ejemplo, al filtrar por la sección Deportes, se da la posibilidad de volver a filtrar por el tipo de deporte, Ciclismo.

En este caso, se ha buscado por palabras clave (vuelta + ciclista + España) obteniendo 883 resultados. Se ha afinado filtrado por año 2017 con 40 resultados, por sección Deportes con 17, y por Ciclismo obteniendo 15 noticias. No constan fotos ni vídeos. Sin embargo, al filtrar por año y deporte se ha detectado que hay contenidos de La Vuelta en la subsección Comunidad Valenciana, pero no aparecen en los resultados de Ciclismo. En este caso es una fotografía. El cibermedio no ofrece posibilidad de filtrar por infografía.

Al revisar una por una las noticias obtenidas, se observa que integrados en las noticias hay vídeos, infografías y fotografías. Sin embargo, como se ha demostrado filtrando por fotografías o vídeos, el cibermedio no identifica estos contenidos individualmente como tales ni ofrece modo para acceder a estos si no es pasando por la noticia en la que están publicados. Un ejemplo es la noticia con imágenes e infografías "La etapa 18 de la vuelta, en vivo" (ir al sitio) que contiene fotos e infografías.

Además, tras un repaso general de contenidos, se observa que algunas noticias son informaciones relacionadas con los ciclistas o incidencias, pero no aportan información de La Vuelta Ciclista como acontecimiento deportivo. Ejemplo es la noticia "Un detenido por incendiar el autobús del equipo Aqua Blue Sport de la Vuelta en Almería" (ir al sitio). De las 15 noticias, 8 hacen referencia directa a La Vuelta, 6 a informaciones complementarias de ciclistas, equipos, incidencias, etc., y 1 no tienen que ver con La Vuelta en absoluto.

Si usamos el sistema de navegación, se accede rápidamente a la sección Deportes y la subsección Ciclismo y, dentro de esta, a Vuelta a España y, a modo de menú, hay tres tipos de información: Clasificación, Etapas y Palmarés.

En la página Vuelta a España, se localizan 49 noticias. En esta misma página, en el marco derecho, figura un resumen de la Clasificación General que enlaza con otro nodo que muestra, organizada en una tabla, la información al completo, y otro resumen de la Epata 21, que enlaza con un nodo que contiene, a modo de micro sitio dirigido por un menú, el acceso a las tablas 
que muestran la clasificación de las 21 etapas. De las 49 noticias, 40 hacen referencia directa a La Vuelta y 6 a informaciones complementarias de ciclistas, equipos, incidencias, zonas de paso, etc. Se aprecia que los resultados obtenidos mediante el Buscador no coinciden con los de la navegación por menús.

El submenú Clasificación enlaza con la página Clasificación General explicada líneas anteriores. El submenú Etapas dirige a la página Etapas de la Vuelta a España 2017 con una infografía autónoma que ubica al lector visualmente las diferentes etapas y sus recorridos. Y el submenú Palmarés enlaza con la página Palmarés - Vuelta a España 2000-2016, en la que se encuentra una tabla cronológica con la información principal de los ganadores de los tres primeros puestos de La Vuelta en ese periodo de tiempo.

En una lectura general del contenido de las 49 noticias halladas, sea por buscador o por menús, se observa que casi todas enlazan con dos secciones dedicadas exclusivamente a La Vuelta como son Narración y estadísticas, con contenidos de las diferentes etapas narradas textualmente, y Clasificación general. Así que el siguiente paso ha sido localizar estos espacios dentro del cibermedio.

Clasificación sí está accesible desde la subsección Ciclismo, Vuelta a España, pero Narraciones y Estadísticas no. Para poder encontrar esta página y obtener una muestra de estudio más precisa, se ha probado navegando por el menú principal, concretamente en la sección Más donde se han encontrado dos subsecciones: El Mundo Data (ir al sitio) y Gráficos (ir al sitio). La primera ofrece noticias o infografías basadas en información de datos contextualizándolos o comparándolos. Se ha encontrado dos tipos de contenidos: uno que se identifican con un icono descrito como Grafico; y otro contenido sin identificación visual. A simple vista parece que la diferencia es que las noticias con el icono Grafico son o integran infografías dinámicas. Esto es, con interactividad o datos dinámicos apoyados en bases de datos dinámicas. El resto de noticias son o se complementan con infografías estáticas. En este apartado no se ha encontrado ninguna infografía, o gráfico, como lo denomina el cibermedio, sobre La Vuelta. La segunda subsección, Gráficos, ofrece fotografías e infografías. En este caso, diferencia la imagen de la infografía identificando esta última con el icono personalizado Gráficos, ya sea estática o dinámica indistintamente.

El contenido informativo encontrado sobre la Vuelta ha sido la infografía ya descrita Etapas de la Vuelta a España 2017, y la noticia con infografías y fotos 
Verdades y Falacias sobre el Angliru (ir al sitio) que también se ha accedido a ella desde la subsección Ciclismo, Vuelta a España.

En ninguna de las dos subsecciones se ha encontrado un acceso a Narraciones y Estadísticas. La única vía parece ser a través del enlace de las propias noticias.

De entre las diferentes rutas de acceso a noticias de La Vuelta y la información encontrada y su organización, se puede establecer que la información de La Vuelta Ciclista a España 2017 en elmundo.es está en cuatro sitios: Vuelta a España (ir al sitio), Clasificación General (ir al sitio), Clasificación Etapas (ir al

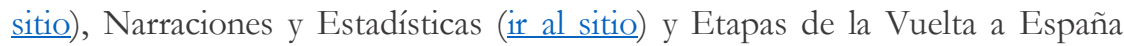
2017 (ir al sitio).

Cabe destacar que Narraciones y Estadísticas no tiene un acceso claro para los usuarios. Y Clasificación Etapas enlaza con una página no usable puesto que el índice numerológico da a entender que vincula con cada etapa pero no funciona.

De las noticias de la subsección Vuelta a España, 4 contienen infografías: Verdades y falacias en el Angliru (ir al sitio), Madrid se prepara para despedir La Vuelta (ir al sitio), Una ascensión de Tour para la Vuelta, 28 kilómetros tras rampas de hasta el 20\% (ir al sitio) y La Vuelta descubre su muro: final inédito en la Ermita de Santa Lucía (ir al sitio).

Clasificación General muestra una tabla con información organizada en orden creciente por la posición de los 159 ciclistas que ofrece datos como el dorsal, nombre, nacionalidad, equipo y tiempo obtenido en la Vuelta de cada uno de ellos. Aunque los datos están organizados, la tabla no se considera infografía en este estudio. Clasificación Etapas sigue las pautas que el caso anterior pero centrándose en cada etapa. Narraciones y Estadísticas se trata de un micrositio que incluye un menú con las 20 etapas. Al pinchar en cada una, se ofrece al lector una narración textual organizada en diferentes inserciones cronológicas, a modo de blog, del acontecimiento. Esta narración está complementada por una infografía y dos tablas: La infografía informa del circuito y los desniveles de la ruta; Las tablas informan del estado de la clasificación de dicha etapa y de la clasificación general. Y Etapas de la Vuelta a España 2017 es una infografía autónoma. Resumiendo, como objeto de estudio se determinan las 4 noticias citadas, Narraciones y Estadísticas y Etapas de la Vuelta a España 2017.

Una vez terminado el análisis de acceso a la información, el estudio se centra en la hipertextualidad e interactividad de estas infografías. 
1) Verdades y falacias en el Angliru es una noticia que incluye una infografía autónoma titulada El puerto más duro y dos textos independientes. Uno sobre los ciclistas que ganaron esta etapa en ediciones anteriores, y otro sobre Froome y sus posibilidades en este puerto. La infografía se compone de tres informaciones: la primera muestra el recorrido ubicando al lector con un mapa e informa sobre la pendiente del terreno con un gráfico; la segunda muestra un gráfico sobre la etapa; y la tercera es un atabla ordenada de las ascensiones más rápidas. Es estática sin hipertextualidad ni interactividad.

2) Madrid se prepara para despedir La Vuelta sigue el mismo patrón. La noticia presenta la infografía titulada La Vuelta acaba en Madrid. Aunque complementa al texto de la noticia, se entiende sin necesidad de leerlo. Se compone de un mapa ubicativo y un plano que amplía y detalla una zona específica del mapa mostrando el circuito al detalle. Es estática sin hipertextualidad ni interactividad.

3) Una ascensión de Tour para la Vuelta, 28 kilómetros tras rampas de hasta el $20 \%$ coincide con el esquema de las noticias 1 y 2 . La infografía complementa al texto y, aunque al situar el curso sobre el área delimitada se muestra el icono de interactividad, no se obtiene ninguna retroalimentación. Parece un enlace roto. Además, la calidad de resolución es deficiente y los datos no se visualizan nítidos.

4) La Vuelta descubre su muro: final inédito en la Ermita de Santa Lucía sigue el mismo modelo que la noticia 3.

5) Narraciones y Estadísticas enlaza con la narración de las 21 etapas y, complementado el texto de cada narración, hay una infografía que describe el desnivel de la etapa con una ilustración. Es estática sin hipertextualidad ni interactividad.

6) Etapas de la Vuelta a España 2017 es una infografía autónoma. Tienen hipertextualidad e interactividad. Se compone por: Un gráfico circular resumen de la dificultad de las etapas en total; Un mapa interactivo de España con los recorridos. Al pinchar en cada etapa se muestra un gráfico del recorrido con el desnivel sustituyendo al gráfico circular resumen; Además, hay un menú ilustrado en la parte superior con las 21 etapas que, al pinchar sobre cada una de ellas, se muestra el mismo gráfico del recorrido de la etapa. Se trata de un hiperdocumento basado en una estructura multilineal arbórea. Aunque toda la información se organiza en un único nodo, se presentan varias alternativas de lectura manteniendo un mismo eje en el discurso. Sí hay profundidad de información pero en un único nivel, limitándose a mostrar u 
ocultar información en el mismo nodo. Los enlaces, aunque no se perciben a imple vista como pulsadores diferenciados del resto de elementos gráficos, funcionan correctamente y todos son imágenes gráficas. Respecto a la interactividad, se basa en pulsadores a modo de menú o integrados en las ilustraciones para que el lector/usuario seleccione la información y el recorrido de lectura. En todos los casos, al pinchar sobre el pulsador, se muestra una información que es sustituida al clicar sobre otro pulsador. No hay manipulación de los contenidos, sólo en cuanto a la elección del recorrido de lectura. La hipertextualidad e interactividad son básicas limitándose a la navegación.

Figura 4. Infografía: Etapas de la Vuelta Ciclista a España 2017.

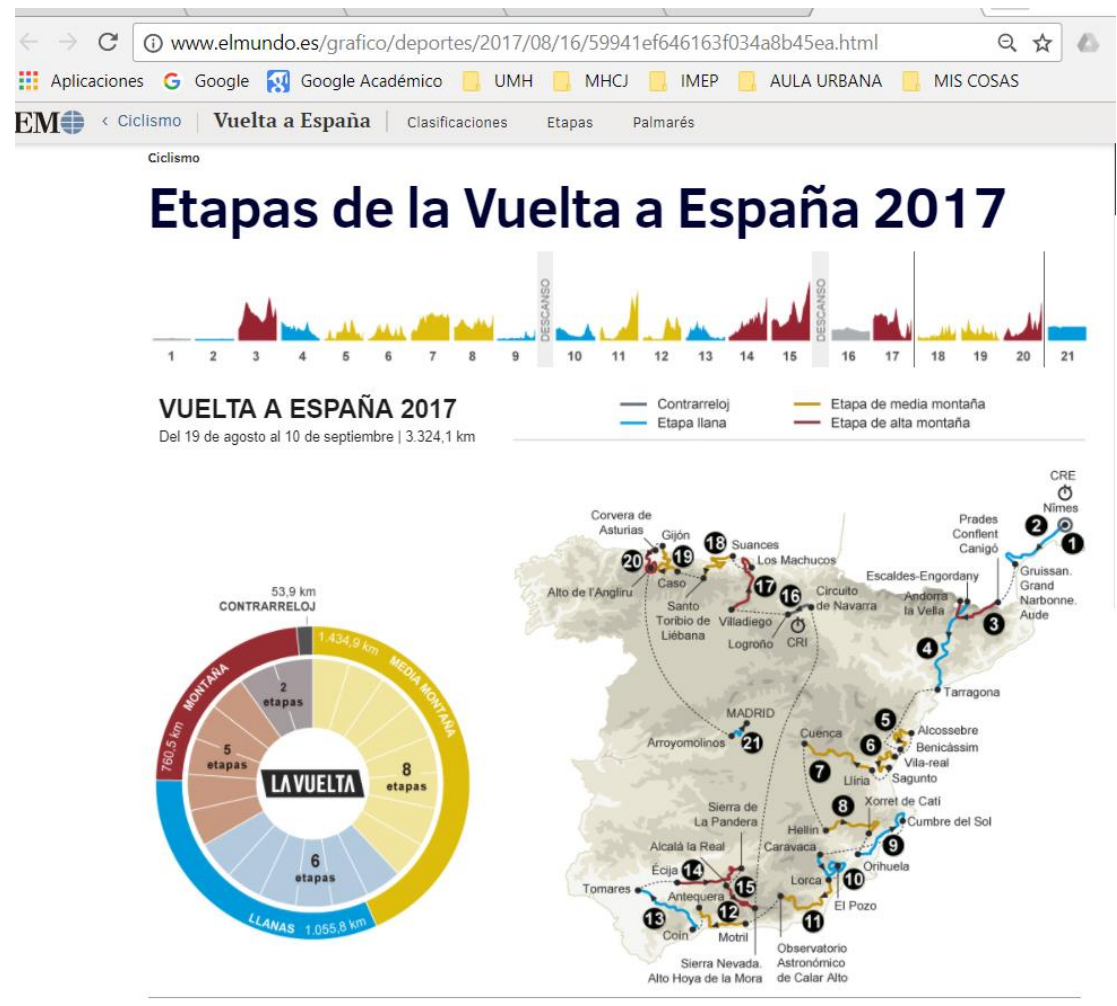

Fuente: Elmundo.es. 2017. 


\section{Discusión}

En el caso de la memoria, en cuanto al acceso y recuperación de contenidos, es de suponer que en una subsección concreta, como puede ser La Vuelta a España, se debería mostrar/almacenar toda la información sobre el asunto. También se da por sentado que, al hacer consultas mediante el buscador usando las palabras clave contenidas en la descripción del menú desde el que se accede a la subsección, los resultados deberían ser idénticos a los encontrados en la misma. Sin embargo, no es así. Se aprecia que los resultados obtenidos mediante el Buscador no coinciden con los de la navegación por menús.

Para obtener todas las noticias de un asunto concreto, se ha tenido que ir sumando los resultados de búsqueda obtenidos mediante las dos herramientas de recuperación: buscador interno y opciones de navegación (menús y enlaces internos en las noticias). Cada instrumento ha proporcionado datos diferentes. A pesar de que el buscador ofrece diversas posibilidades de filtrado para conseguir una búsqueda más precisa, no se obtienen resultados reales confundiendo al usuario o dejándolo desinformado.

En cuanto al tipo de contenido, sucede lo mismo. No se entiende bien la distinción entre gráficos, gráficos dinámicos y fotografías. Además, parece no existir sistema de etiquetado en cuanto a la temática de la pieza visual o audiovisual puesto que mediante el buscador sólo se ha localizado una fotografía y, sin embargo, todas las noticias incluyen foto, vídeo o gráfico.

Si nos centramos en la infografía, elmundo.es identifica la infografía periodística como un gráfico. Éstos pueden encontrarse en la sección Más, Gráficos. Incluso, el medio ha creado otra subsección para este tipo de informaciones denominada El mundo en Datos, donde ubica las noticias con infografías de datos numéricos exclusivamente y las diferencia entre estáticas o dinámicas. El resto de infografías descriptivas, de contextualización o ubicativas parecen estar englobadas en la sección Más, Gráficos.

La Vuelta ciclista a España es un acontecimiento planificado con meses de antelación, sin embargo esto no ha propiciado una infografía más elaborada en cuanto a hipertextualidad o interactividad. Todos los casos observados menos uno son estáticos donde la infografía complementa al texto. Cuando hay excepción, la hipertextualidad e interactividad son básicas limitándose a pulsadores para mostrar u ocultar información en un único nodo. Aunque toda la información se organiza en un nodo con menú que deja elegir el orden 
lectura pero manteniendo un mismo eje discursivo, sí hay profundidad de información pero en un único nivel.

\section{Conclusiones}

Elmundo.es no explota la memoria, la interactividad y la hipertextualidad como cabe esperar del segundo cibermedio más leído en España. El concepto de cibermedio debe estar directamente relacionado con el medio Internet y las características comunicativas que lo conforman. Esto es, un lenguaje propio definido por la hipertextualidad e interactividad principalmente cuya dirección va en sentido de potenciar la personalización de contenidos e inmersividad por parte del usuario. No se trata de la cantidad de información que se ofrece, sino más bien de cómo se le ofrece al usuario. No basta con elaborar documentos de estructuras mixtas que permitan profundizar completando y complementando la información, o integrar múltiples herramientas o servicios de valor añadido. Hay que ir más allá reforzando la lectura y exploración con experiencias accesibles, usables, personalizadas e inmersivas para captar y retener al lector.

La hipertextualidad y la interactividad están presentes en el cibermedio pero se centran principalmente en la navegación. Aunque las piezas textuales sí se basan en estructuras hipertextuales arbóreas o mixtas, se limitan a ofrecer caminos de lectura. Con la interactividad sucede algo similar en cuanto a que para navegar, el usuario debe interactuar con los pulsadores, sean menús u otro tipo de enlaces. Entiéndase como pulsador cualquier enlace textual o de otra naturaleza que permite desencadenar una acción. Por lo que la interacción del lector se basa en moverse entre nodos o en mostrar/ocultar información en el mismo nodo.

La infografía periodística se considera una noticia en el sentido de que es una pieza informativa. Narra, contextualiza o muestra información pero en vez de emplear el texto, la imagen gráfica adquiere el protagonismo por exigencias del tipo de información que se quiere comunicar. En estas piezas gráficas, el uso de la hipertextualidad es más limitado aún que las textuales aplicándose rara vez. La interacción del usuario se limita a elegir su recorrido de lectura pinchando sobre menús o botones para obtener más información. No hay otro tipo de manipulación ni posibilidad que ofrezca una experiencia de uso particular que fomente la implicación del usuario y por tanto su sentido de participación.

La cabecera española elmundo.es se sitúa en la tercera fase de desarrollo en cuanto la evolución de los sistemas de acceso y recuperación de la información 
por las herramientas que ofrece, pero eso no significa que la calidad de uso de estos instrumentos satisfaga las necesidades de los usuarios. Aunque ofrece suficientes herramientas y posibilidades de filtrado para afinar una búsqueda, parece haber un problema de etiquetado al almacenar los contenidos publicados, por un lado, y de organización de la información por otro. La recuperación de información es confusa y poco eficiente generando desconfianza.

Determinar la muestra de estudio para esta investigación ha sido complejo por las barreras de acceso a la información en los cibermedios, lo cual ha sido determinante en la elección del medio a estudiar: elmundo.es descartando otros. En este caso, los resultados se ciñen a un caso concreto pero las conclusiones alcanzadas, abren las puertas a una futura investigación centrada en el acceso infografías en otros cibermedios generalistas españoles para valorar el panorama español en general a este respecto.

\section{Bibliografía}

Abadal, E y Guallar, J. (2010). Prensa digitaly bibliotecas. Gijón: Trea.

Alexa, Base de datos internacional (2017). Recuperado de http://www.alexa.com/topsites/countries;0/ES

APM (2016): Informe Anual de la Profesión Periodística 2016. Recuperado de http://www.apmadrid.es/publicaciones/informe-anual-de-la-profesion/

Alzamora, G. (2004). "A semiose da informação webjornalística”. En Brasil, A., Falci, C.H., Jesis, E. y Alzamora, G. (Eds.), Cultura em fluxo: novas mediações em rede (pp.100-125). Belo Horizonte: Ed. PUC Minas.

Barbosa, S. (2005). Bases de dados e webjornalismo: em busca de novos conceitos. Recuperado de http://www.bocc.ubi.pt/ esp/autor.php?codautor $=690$

Bardoel, J. y Deuze M. (2001). Network journalism: converging competentes of old and new media professionals. Recuperado de http://home.pscw.nl/deuze/pub/9.htm.

Borras, Leticia at adl. (2000). "Infototal, inforrelato e infopincel. Nuevas categorías que caracterizan la infografía como estructura informativa". Revista Latina de Comunicación Social, 35 / Extra Argentina. Recuperado de http://www.ull.es/publicaciones/latina/Argentina2000/17borras.htm 
Canavilhas, J. (2001). Webjornalismo. Considerações gerais sobre jornalismo na web. Recuperado de http://www.bocc.ubi.pt/pag/canavilhas-joao-webjornal.pdf.

--- (2007b).Webnoticia. Propuesta de modelo periodístico para la wmw. Covilhã: Labcom.

--- (2010). "Los retos del webperiodismo: lenguaje, recursos humanos y modelos económicos". En Ivars Nicolás, B. (ed.). I Congreso Internacional de Comunicación Audiovisual y Publicidad: Internet y la información. Alicante: Limencop. Pp. 50-65. Recuperado de http://www.in2web.es/cicap/publicaciones/internetylainformacion.pdf

Centelles, Miquel. "Taxonomía para la categorización y la organización de la información en sitios web". Hipertext.net, 2005. Recuperado de http://www.hipertext.net/web/pag264.htm

Carvalho, M. (2005). "Mapeamento e produçao de sentido: os links no hipertexto". En Marcuschi, A. y Xavier, A. C. Hipertexto e gêneros digitais. Rio de Janeiro: Lucerna.

Codina, L. (2002). "Información documental e información digital”. En López Yepes, J. (coord.). Manual de Ciencias de la Documentación, Madrid: Pirámide.

--- (2003). "Hiperdocumentos: composición, estructura y evaluación". En Díaz Noci, J. y Salaverría, R. (coords.). Manual de Redacción Ciberperiodística. Barcelona: Ariel.

Coutin, A. (2002). Arquitectura de la Información para sitios Web. Anaya Multimedia.

Dee-Lucas, D. (1996). "Effects of overview structure on study strategies and text representations for instructional hypertext”. En Rouet, J.F.; Levonen, J. J.; Dillon, A. y Spiro, R. J. (eds.). Hypertext and cognition. Mahwah, NJ: Lawrence Erlbaum.

De Pablos, J. M. (1991). "La infografía, el nuevo género periodístico". Libro colectivo Estudios sobre tecnologías de la información, 1. Madrid: Editorial Sanz y Torres, pp. 153-190. Recuperado de http://www.ull.es/publicaciones/latina/a/02mcolle.htm

--- (1993). "Infografía o infoperiodismo, el nuevo género periodístico: ¿cómo y cuándo?”. Comunicación y Sociedad, núm. 18-19, mayo-diciembre. Pp. 257-277.

Díaz Noci, J. y Salaverría, R. (coords.) (2003). Manual de Redacción Ciberperiodística. Barcelona: Ariel S.A. 
--- (2008). "Definición teórica de las características del ciberperiodismo: elementos de la comunicación digital". En doxa.comunicación n ${ }^{\circ} 6$.

Estudio General de Medios. Resumen General de resultados EGM. Recuperado de http://www.aimc.es/-Datos-EGM-Resumen-General-html

Gago, M. (2006). "La arquitectura de la información, ingeniería del periodismo". En López, Xosé (coord.). Sistemas digitales de información. Madrid: Pearson.

Hall, J. (2001). Online journalism: a critical primer. London: Pluton Press.

Ivars Nicolás, B. (ed.) (2010). "I Congreso Internacional de Comunicación Audiovisual y Publicidad: Internet y la información”. Alicante: Limencop.

--- (2012a). Herramientas Web en el proceso de enseñanza y aprendizaje del ciberperiodismo en la Comunidad Valenciana. Revista Mediterránea de Comunicación, vol.3, $\mathrm{n}^{{ }^{a}} \quad 2, \quad 1-30 . \quad$ Recuperado de http://www.rmedcom.org/2012/1207/1207Ivars.htm

--- (2012b). "Canales alternativos de acceso a la prensa española en internet. La noticia fuera del periódico". El profesional de la información, 2012a, julioagosto, v. 21, n. 4, pp. 396-400.

--- (2016). "Las infografías en línea de elpais.com para los JJ. OO. Río 2016: Accesibilidad, usabilidad y diseño de la información.", en Innovar en Periodismo: Mobile First. Comunicación Multipantalla. XI Jornadas Internacionales de Periodismo 2016. Murcia; Diego Marín Librero Editor. Pp.147-156

López García, X.; Gago Mariño, M.y Pereira Fariña, J. (2002). Novas tendencias do xornalismo electrónico. Santiago de Compostela: Edicións Lea.

López García, X.; Limia, M.; Isasi, A.; Pereira, X.; Gago, M.; Calvo, R. y Orihuela, J. L. (2005). "Tipología de los cibermedios". En Salaverría, R. (coord.). Cibermedios. El impacto de Internet en los medios de comunicación en España. Sevilla: Comunicación Social, pp. 39-82.

Marcuschi, L. A. (1999). "Linearizaçâo, cogniçâo e referência: O desafio do hipertexto". En Linguas, instrumentos lingüísticos. Campinas: Pontes, pp. 21-46.

Martínez Ochoa, B. E. (2009). Tesis doctoral: La infografía digital, una nueva forma de comunicación. Facultad de Ciencias de la Comunicación. Universidad Autónoma de Barcelona. 
Martínez-Rubio, R. "La recuperación de la información en los peri- ódicos digitales valencianos". En: López-García, Guillermo (ed.). Comunicación local y nuevos formatos periodísticos en internet: cibermedios, confidenciales y weblogs. Valencia: Servei de Publicacions de la Universitat de València, 2008, pp. 99-140. Recuperado de http://www.cibermediosvalencianos.es/comloc/Martinez.pdf

Mielniczuk, L. (2003). Sistematizando alguns conhecimentos sobre jornalismo na web. En E. Machado y M. Palácios, (Eds.), Modelos de Jornalismo Digital (pp.37-54). S. Salvador: Ed. Calandra.

Mielniczuk, L. (2003). Jornalismo na web: uma contribuição para o estudo do formato da notícia na escrita hipertextual. (Tesis doctoral en la Universidade Federal da Bahia).

Murad, A, (1999) Oportunidades e desafios para o jornalismo na Internet. Ciberlegenda, 2. Recuperado el 3 de marzo de 2002 desde http://www.uff.br/mestcii/angele1.htm.

Palácios, M. (2003) Ruptura, continuidade e potencialização no jornalismo online: o lugar da memória. En Machado y Palácios (Eds.), Modelos de Jornalismo Digital (pp. 13-36). S. Salvador: Ed. Calandra

Peltzer, G. (1991). Periodismo iconográfico. Ediciones Rialp. Madrid

Pereira, X. (2006). "La presencia gráfica del sistema (front-end)". En López

García, X. (coord.). Sistemas digitales de información, Madrid: Pearson.

Powell, T. A. (2001). Diseño de sitios Web. Madrid: McGraw-Hill.

Neiman, G; Quaranta, G. (2006). "Los estudios de caso en la investigación sociológica". Vasilachis de Gialdino (comp.) Estrategias de investigación cualitativa. Buenos Aires: Gedisa

Ribas, B. (2004). Infografía multimídia: um modelo narrativo para o webjornalismo. Recuperado de http://br.m onografias.com/trabalhos/infografia-multimidia-modelonarrativowebjornalismo/ infografia-multimidia-modelo-narrativo-webjornali smo.shtml. 
Rodríguez Yunta, L.; Giménez Toledo, E. (2004). "Más allá de la usabilidad: características mínimas exigibles para las interfaces de bases de datos web”. BiD: Textos universitaris de biblioteconomia $i$ documentació, (13).

Rost, A. (2006). La interactividad en el periódico digital. Tesis doctoral presentada en la Universitat Autònoma de Barcelona.

Rovira, C. (2002a). "Estructuras de navegación para e-learning". En El profesional de la información, vol. 1, núm. 6, novembre-desembre, pp. 457-466.

Rovira, C. (2002b). "Hypertext representation for education and learning". En Interactive Educational Multimedia, núm. 5.

Sádaba Chalezquer, M. R. (2000). "Interactividad y comunidades virtuales en el entorno de la World Wide Web”. En Comunicación y Sociedad, vol. xiii, n 1 , Pamplona: Universidad de Navarra, pp. 139-166.

Salaverría, R. (2005a). Redacción periodística en Internet. Navarra: Ediciones Universidad de Navarra, S.A. (EUNSA).

Salaverría, R. (coord.) (2005b). Cibermedios. El impacto de Internet en los medios de comunicación en España. Sevilla: Comunicación Social.

Salaverría, R. (2008a). "Ciberperiodismo: diez años de prensa digital en España”. En Fernández Sanz, J. J. (ed.). Prensa especializada actual. Doce calas. Madrid: McGraw-Hill, pp. 355-383.

Serra, J. (1998). ¿Tenemos la información visual necesaria para hacer un gráfico? Mimeo.

Toschi, L. (2001). Il linguaggio dei nuovi media. Web e multimedia: principe e tecniche delle nuove forme di comunicazione. Milano: Apogeo.

Yin, R. (1994). Case study research: Design and methods. California: Sage. 


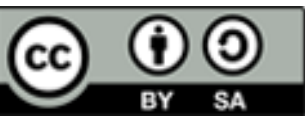

Licencia Creative Commons

Miguel Hernández Communication Journal

mhjournal.org

\section{Cómo citar este texto:}

Begoña Ivars Nicolás (2017): "El tratamiento de la información infográfica de La Vuelta Ciclista a España 2017 en elmundo.es”, en Miguel Hernández Communication Journal, nº, pp. 671 a 698. Universidad Miguel Hernández, UMH (Elche-Alicante). Recuperado el__ de de 20_ de: [link del artículo en mhjournal.org] 